\title{
Derivatization, characterization, and tribological behavior of an amine-terminated polymer surface
}

\author{
S.L. Ren ${ }^{\mathrm{a}, \mathrm{b}}$, S.R. Yang ${ }^{\mathrm{a}}{ }^{*}$, Y.P. Zhao ${ }^{\mathrm{b}}$ \\ ${ }^{a}$ State Key Laboratory of Solid Lubrication, Lanzhou Institute of Chemical Physics, \\ Chinese Academy of Sciences, Lanzhou 730000, China \\ ${ }^{\mathrm{b}}$ State key Laboratory of Nonlinear Mechanics, Institute of Mechanics, \\ Chinese Academy of Sciences, Beijing 100080, China
}

Received 17 October 2003; received in revised form 3 December 2003; accepted 3 December 2003

\begin{abstract}
The derivatization, characterization, and micro-tribological behavior of an amine-terminated polymer surface were investigated. Thus, the heptafluorobutyric anhydride (HFBA) derivatized film was characterized by means of contact-angle measurement and X-ray photoelectron spectroscopy (XPS). It was found that the HFBA-derivatized film was generated on the PEI surface in the presence of a chemical amide bond. The tribological properties were characterized as well. The polymer PEI film had relative high adhesion, friction, and poor anti-wear ability, while the HFBA-derivatized polymer film possessed a very low adhesive force of only about $5.5 \mathrm{nN}$ (a pyramidal $\mathrm{Si}_{3} \mathrm{~N}_{4}$ tip with radius of curvature about 50 nm was used to measure the adhesion), which was more than an order of magnitude lower than that of the silicon substrate surface. Besides, the HFBAderivatized film registered good friction-reducing ability and thermal stability. Thus, a good alternative method was presented to improve the tribological properties of polymer film by chemisorbing molecules with low surface energy. This makes it feasible for the derivatized polymer film to find promising application in resolving the tribological problems of micro-electromechanical systems (MEMS).
\end{abstract}

(C) 2003 Elsevier B.V. All rights reserved.

Keywords: Polymer film; Derivatization; Adhesion; Friction; Thermal stability; MEMS

\section{Introduction}

Micro-electromechanical systems (MEMS) are known for their wide potential use and low unit cost. However, the large surface-area-to-volume ratios raise serious adhesive and frictional problems for their

\footnotetext{
* Corresponding author. Tel.: +86-931-8277851; fax: +86-931-8277088.

E-mail addresses: slren@1sl.ac.cn (S.L. Ren), sryang@ns.lzb.ac.cn (S.R. Yang).
}

operations [1-3]. In order to resolve the adhesive and friction-related problems of MEMS, it is strongly suggested to modify the surface of the micro-devices. This accounts for the increased attention to the polymer thin films with promising application perspectives as protective coatings, adhesion-resistant materials, and boundary lubricants [4-7].

Polymers containing polar groups were capable of forming stable thin film via the multiple functional groups strongly attached to the substrate [8-15]. However, due to the strong polar groups contained in the polymer, such polymer surface would be hydrophilic. 
In other words, these polymer films would possess high surface energy, which could increase the adhesion and friction especially on a micro-scale. This has been demonstrated by Bradley and co-workers [7]. They reported that the frictional force would increase with increasing polarity of a polymer surface. Fortunately, the polymer films with low surface energy could be obtained by tailoring the exposed groups from polar group to apolar group [9]. For example, marked stick-slip sliding behavior on a hydroxylexposing surface disappeared after introducing a methyl group to replace the hydroxyl group in the polymer [10,11]. But, it can be speculated that the wear-resistance of the polymer film would be decreased since the combined force for the methyl group combining with the substrate would become weaker than that of the hydroxyl group.

From our viewpoint, a good alternative approach to prepare polymer thin film with low adhesion, friction, and high wear-resistance was by first selecting functional polymer generated on the substrate and then through surface chemical derivatization to produce hydrophobic surface. The resulting polymer film would not only be stably combined with the substrate via the polar groups, but also exposed a hydrophobic surface with low surface energy. Though many efforts have been made on the chemical derivatization of functional polymer surface [16-23], few works are engaged in tribological studies. With this perspective in mind, we selected branched polyethyleneimine \{abridged as PEI,$\left.\left[\mathrm{C}_{2} \mathrm{H}_{5} \mathrm{NHC}_{2} \mathrm{H}_{5} \mathrm{~N}\left(\mathrm{C}_{2} \mathrm{H}_{5} \mathrm{NH}_{2}\right) \mathrm{C}_{2} \mathrm{H}_{5} \mathrm{NH}\right]_{n}-\right\}$ to carry out our research on the derivatization, characterization, and tribological behavior of an amine-terminated polymer surface. PEI has a distribution of primary, secondary, and tertiary amine-groups in a ratio of 1:2:1 and can be easily adsorbed onto any hydroxylated solid surfaces through hydrogen bonds and van der Walls forces [18,24-26]. Furthermore, the primary and secondary amine-groups can be readily modified by phosgene, thiophosgene, cyanuric chloride, and glutaraldehyde [24]. We dealt with the preparation of a fluorinated surface with low surface energy by vapor-phase chemical derivatization of a PEI-coated silicon substrate in a previous communication [27]. In the present article, the micro-tribological properties and thermal stability of the film are focused on.

\section{Experimental}

\subsection{Materials}

Polished and cleaned single-crystal silicon( $\left.\begin{array}{lll}1 & 1 & 1\end{array}\right)$ wafer (obtained from GRINM Semiconductor Materials Co. Ltd., Beijing) with root mean square (RMS) roughness of about $0.3 \mathrm{~nm}$ over a range $1 \mu \mathrm{m} \times 1 \mu \mathrm{m}$ was used as the substrate. The aqueous solution of PEI $\left(M_{\mathrm{W}}=50,000-60,000\right)$ at a mass fraction of $50 \%$ was obtained from ACROS (New Jersey, USA). Heptafluorobutyric anhydride (HFBA, purity 99\%) was obtained from Fluka (Switzerland) and used as received.

\subsection{Preparation of the fluorinated film}

The silicon wafers were firstly cleaned and hydroxylated by immersing in a piranha solution (a mixture of $7: 3(\mathrm{v} / \mathrm{v}) 98 \% \mathrm{H}_{2} \mathrm{SO}_{4}$ and $\left.30 \% \mathrm{H}_{2} \mathrm{O}_{2}\right)$ at $90{ }^{\circ} \mathrm{C}$ for $30 \mathrm{~min}$. The cleaned wafers were then placed into a dilute aqueous solution of PEI ( $0.2 \mathrm{wt} . \%)$ and held for $15 \mathrm{~min}$. After rinsing with ultra-pure water and flushed with $\mathrm{N}_{2}$ gas, a thin layer of PEI was formed on the hydroxylated silicon surface. The vapor-phase derivatization of the PEI-coated silicon substrates in the presence of HFBA was realized in an enclosed roundbottom flask at ambient conditions $(\mathrm{RH}=30 \%)$. Finally, the samples were sequentially ultrasonically cleaned with ethanol and acetone to get rid of the physisorbed impurities.

\subsection{Characterization of the film}

The static contact angles for ultra-pure water on the films were measured with a Kyowa contact-angle meter. At least five replicate measurements were carried out for each specimen, and the measurement error was $\pm 1^{\circ}$.

The chemical states of the elements in the ultrahydrophobic surface were determined on a multifunctional X-ray photoelectron spectroscope (PHI5702, Perkin-Elmer, USA), using the $\mathrm{Mg} \mathrm{K} \alpha$ line as the excitation source and at a pass energy of $29.4 \mathrm{eV}$. The binding energy was measured to an accuracy of about $\pm 0.3 \mathrm{eV}$, using that of the hydrocarbon (C 1s: $284.6 \mathrm{eV}$ ) as the reference.

The micro-tribological behaviors of the films were characterized on an AFM/FFM controlled by RHK 
electronics (RHK Technology, Rochester Hills, MI, USA). Commercially available $\mathrm{Si}_{3} \mathrm{~N}_{4}$ cantilevers/tips with a nominal force constant of $0.5 \mathrm{~N} / \mathrm{m}$ and the pyramidal tip radius of curvature about $50 \mathrm{~nm}$ (Park Instruments, Sunnyvale, CA, USA) were employed. To obtain the adhesive force between the AFM tip and the film surface, the force-distance curve was recorded and the pull-off force reckoned as the adhesive force. All the friction and adhesion tests were conducted at room temperature about $21{ }^{\circ} \mathrm{C}$ and relative humidity about $65 \%$.

\section{Results and discussion}

\subsection{Derivatization and characterization}

Measurements of contact angle provide a sensitive probe of the chemical composition, order, and coverage of organic thin films on solid surface. Thus, the contact angles for water on the hydroxylated silicon surface and the target films were measured. The hydroxylated silicon surface and the PEI coating are hydrophilic and have water contact angles about $0^{\circ}$ and $9^{\circ}$, respectively. After keeping the PEI-coated substrate in the HFBA vapor for $24 \mathrm{~h}$, the contact angle greatly increases to $103^{\circ}$, reflecting that the hydrophobic fluorinated film has been produced. Hutt and Leggett [28] investigated the derivatization of a hydroxyl-terminated SAMs on a gold surface in the presence of HFBA molecules and found that the resulting film possessed a contact angle of nearly about $115^{\circ}$, which is larger than what is observed in our experiment. This reflects that the target HFBA film in our work is not densely packed enough, which might attribute to a lower content of amine-groups on the PEI surface or an incomplete derivatization of the amine-groups.

The adsorption kinetics of HFBA onto the PEIcoated silicon surface was also investigated by plotting the variation of the contact angles with the adsorbing time. As shown in Fig. 1, the contact angles increase quickly at the early-stage of adsorption and gradually rise to the maximum value about $103^{\circ}$ at an extended adsorption duration, which is similar to the adsorption kinetics of alkanethiol onto Au(l 111$)$ surfaces described by diffusion-controlled Langmuir adsorption, which was found to strongly depend on

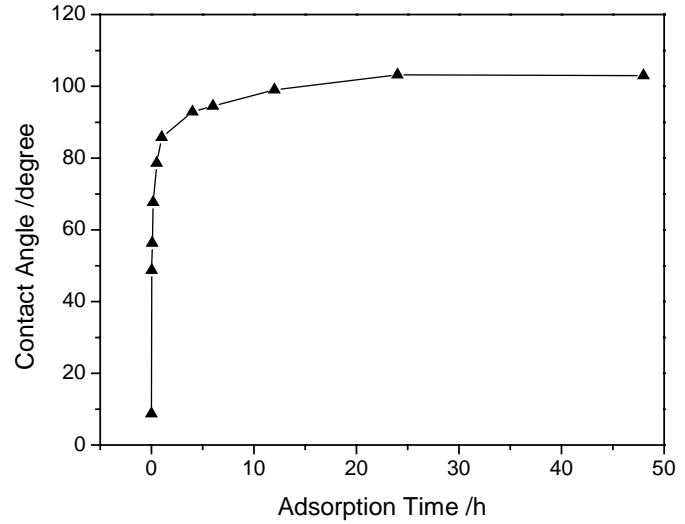

Fig. 1. Variation of water contact angles with adsorbing time for PEI surface exposed to vapor of HFBA.

the thiol concentration [29]. Moreover, as seen in Fig. 1, the complete adsorption of HFBA-derivatized film on the PEI surface is realized at an adsorption duration of $24 \mathrm{~h}$ when the contact angle keeps unchanged with increasing adsorption duration. Therefore, the PEI-coated Si substrate was kept in the vapor of HFBA for $24 \mathrm{~h}$ to allow the preparation of the fluorinated film specimens for the characterization in our work.

In order to get an insight of the interaction between HFBA and PEI, we performed XPS analysis on the HFBA-devrivatized thin film and the results are shown in Fig. 2. A large and highly symmetrical $F$ 1s peak appears at $688.3 \mathrm{eV}\left(\mathrm{C}-\mathrm{F}^{*}\right)$, which is assigned to the $\mathrm{F}$ element in the HFBA-derivatized film (Fig. 2a). Besides, four peaks of $\mathrm{C} 1 \mathrm{~s}$ are identified in Fig. $2 \mathrm{~b}$. The peak at $284.6 \mathrm{eV}$ is attributed to the $\mathrm{CH}_{2}$ group in $\mathrm{PEI}$, that at $285.8 \mathrm{eV}$ might be assigned to the $\mathrm{C}$ atoms bonded to the amide group $\left(\mathrm{O}=\mathrm{C}-\mathrm{N}-\mathrm{C}^{*}\right)$ [18]. The $\mathrm{C}$ $1 \mathrm{~s}$ peak at $288.0 \mathrm{eV}$ corresponds to the carboxyl $\mathrm{C}$ $\left(\mathrm{O}=\mathrm{C}^{*}\right)$, while that at $291.8 \mathrm{eV}$ is assigned to $\mathrm{C}$ attached to $\mathrm{F}\left(\mathrm{C}^{*}-\mathrm{F}\right)$ whose upward shifting is attributed to the strong electron-attraction effect of the most active non-metal $\mathrm{F}$. The above XPS analysis results indicate that chemical reaction occurs between HFBA and PEI. This is further supported by the XPS spectrum of $\mathrm{N}$ 1s (Fig. 2c). While the $\mathrm{N} 1 \mathrm{~s}$ peak at $399.5 \mathrm{eV}$ is assigned to the amine-group, that at $400.6 \mathrm{eV}$ can be attributed to the $\mathrm{N}$ atom bonded to the carbonyl group $\left(\mathrm{O}=\mathrm{C}-\mathrm{N}^{*}\right)[18,30]$. The latter with an upward chemical shift of about $1.1 \mathrm{eV}$ due to the electron-attraction effect of the carbonyl group was 

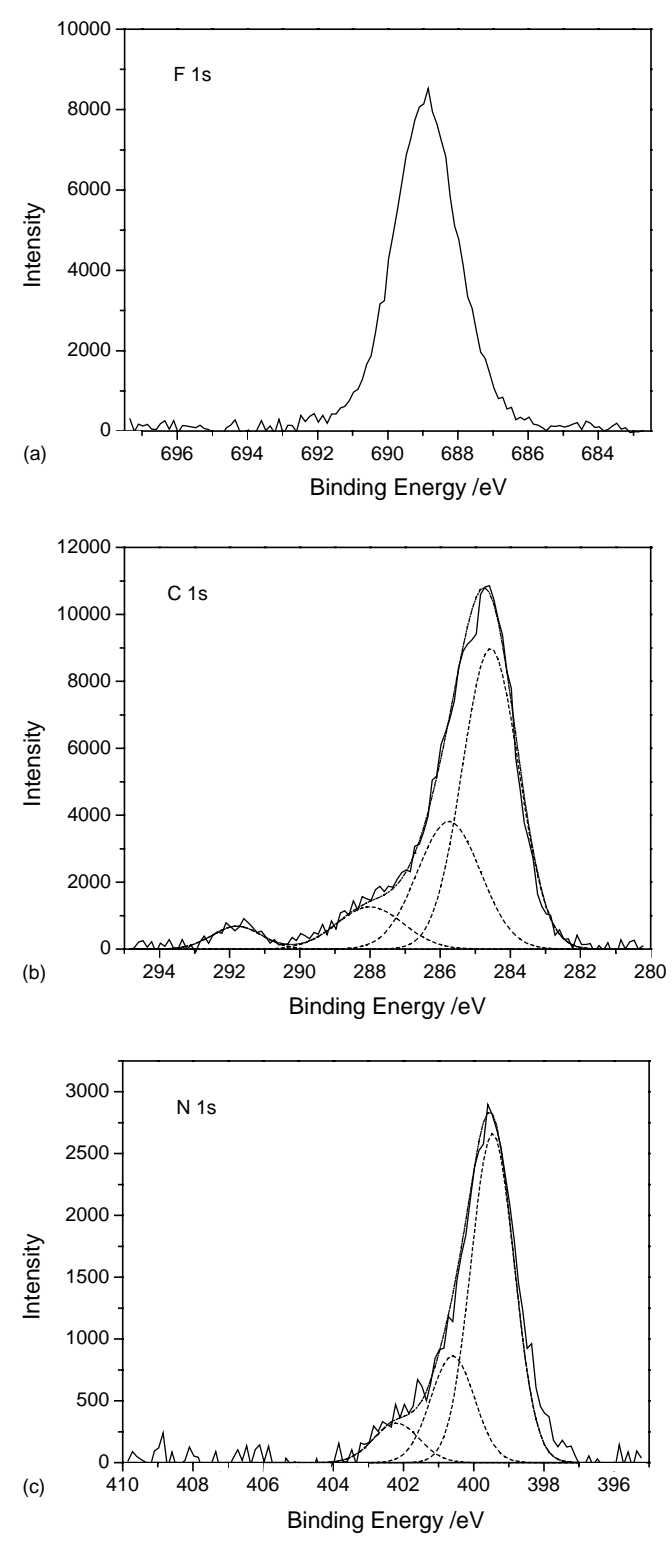

Fig. 2. XPS spectra of the HFBA-devrivatized film on PEI-coated silicon substrate.

also reported previously [18]. Besides, the XPS peak of $\mathrm{N} 1 \mathrm{~s}$ at $402.2 \mathrm{eV}$ might be attributed to the oxidation of some amine-groups in PEI.

From the above-mentioned results, it is concluded that HFBA molecules have successfully chemisorbed onto the PEI-coated silicon surface, which is closely related to the reaction between the PEI surface containing terminal amine-groups and the anhydride by

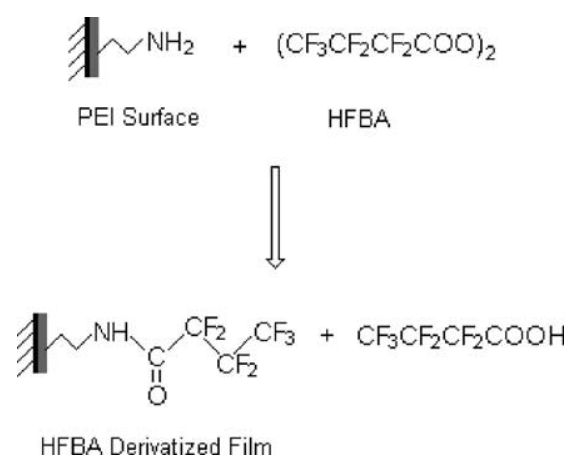

Scheme 1. Derivatization of amine-terminated PEI surface by heptafluorobutyric anhydride.

way of forming covalent amide bond [18]. The reaction process is schematically shown in Scheme 1.

\subsection{Micro-tribological behaviors}

Strong adhesion is observed on the hydroxylated silicon surface, on which the adhesive force is as high as about $70.4 \mathrm{nN}\left(\mathrm{a} \mathrm{Si}_{3} \mathrm{~N}_{4}\right.$ tip with radius of about $50 \mathrm{~nm}$ was used to measure the adhesion). Once the PEI coating and the HFBA-derivatized film are generated, the adhesive forces are greatly decreased to 17.2 and $5.5 \mathrm{nN}$, respectively. This indicates that the HFBA-derivatized thin film can well decrease the adhesion of silicon surface. In combination with the corresponding contact-angle measurement results, it is found that the adhesion forces decrease with increasing contact angles, which is also reported elsewhere [31]. On one hand, this is because the capillary force dominating the adhesion and closely related to the hydrophilicity of a surface would be greatly decreased for a hydrophobic surface [32]. On the other hand, the low surface energy of the fluorinated surface also accounts for the low adhesive force. For example, the surface energy of a fluorocarbon film was reported to be as low as $6 \mathrm{~mJ} / \mathrm{m}^{2}$, which was much lower than that of a hydrocarbon film (e.g., the surface energy of the film composed of $-\mathrm{CH}_{3}$ groups was as large as $24 \mathrm{~mJ} / \mathrm{m}^{2}$ ) [33]. Srinivasan et al. [34] investigated the stiction of the SAMs derived from the precursor molecules of octadecyltrichlorosilane (OTS) and $(1 \mathrm{H}, \quad 1 \mathrm{H}, \quad 2 \mathrm{H}, \quad 2 \mathrm{H})$-perfluorodecyltrichlorosilane (FDTS) which were used as boundary lubricants in polycrystalline silicon micro-structures. They found that the release-related stiction associated with water 
capillary forces was eliminated due to the hydrophobicity of these SAMs, and the in-use stiction was also greatly reduced. In addition, the fluorinated SAMs had greatly reduced adhesion by four times than the OTSSAMs.

It should be pointed out that the PEI film has an adhesion force about $17.2 \mathrm{nN}$ which is considerably lower than that of $70.4 \mathrm{nN}$ of the silicon surface, although the PEI coating is also strongly hydrophilic and shows a water contact angle only about $9^{\circ}$. This reflects that, apart from the capillary force effect, other factors, such as chemical-related forces, may also significantly affect the adhesion. The chemical-related forces might play an important role to the adhesion for the mated surfaces made of the same or similar materials. In other words, the adhesion between $\mathrm{Si}_{3} \mathrm{~N}_{4}$ tip and silicon surface might close related to their high pair interaction (a high pair interaction means that the mated molecules or the atoms are sitting deeply inside their potential well of electron cloud [35]), while it would have little contribution to the adhesion of the PEI film, since the PEI film and the $\mathrm{Si}_{3} \mathrm{~N}_{4}$ tip are very different in nature. Thus, the PEI film could also considerably decrease the adhesion of the silicon surface, although it still possesses a strong hydrophilic property.

The friction-load curves for the hydroxylated silicon surface, PEI coating, and the HFBA-derivatized thin film are shown in Fig. 3. In combination with the adhesion forces of various surfaces, it is rational to observe that both the two films have reduced friction force; especially, HFBA-derivatized thin film possesses much better lubricity. Lots of studies have reported that the friction would decrease with reducing microscopic adhesion [31,36,37]. Apart from the adhesive contribution to friction-reduction, the low shear strength of the organic films also largely accounts for the decreased friction. Israelachvili et al. [38-40] reported that friction force did not directly correlate to the adhesion force (or energy), but had a good correlation to the adhesion hysteresis for the system of both sliding surfaces coated with long-chain monolayers. How much of the adhesion hysteresis of the silicon surface, PEI film, and the HFBA-derivatized film are still unclear. However, we suppose that would be weak since the AFM tip used in this work is not modified by the organic monolayer and thus no molecular inter-digitation occur between

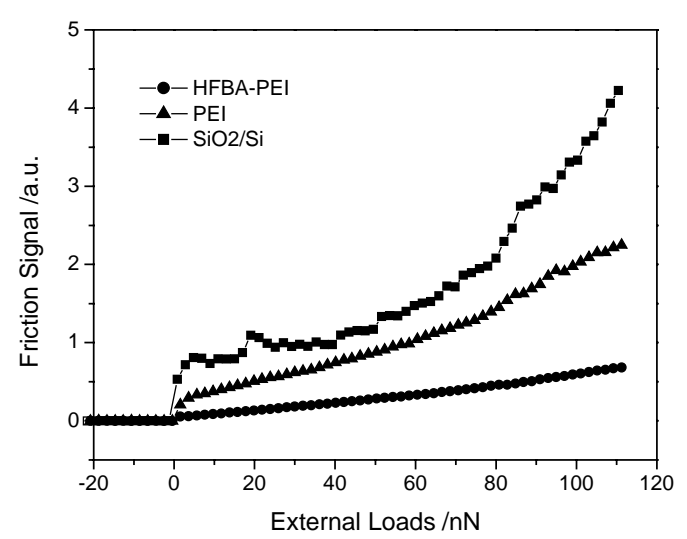

Fig. 3. Friction-load curves for the surfaces of the hydroxylated silicon $\left(\mathrm{SiO}_{2} / \mathrm{Si}\right)$, PEI coating, and the HFBA-derivatized film at a scanning velocity of $0.5 \mu \mathrm{m} / \mathrm{s}(\mathrm{RH}=65 \%)$.

the tip and the sample surface. It has been also reported that ordered fluorinated monolayer possessed a little larger friction force than that of hydrocarbon chain [41-43]. Nevertheless, the fluorinated film generally had much low surface energy and adhesion force, which was significant in resolving the adhesive problem of MEMS. Moreover, the fluorinated film possessed high thermal stability as will be shown later.

Wear information can also be obtained from Fig. 3. The friction curve for the silicon surface is irregular and shows large fluctuation with increasing load, which indicates that wear occurs easily between the Si surface and the AFM tip (see Fig. 3). Up to $80 \mathrm{nN}$, the friction increases slowly, reflecting the occurrence of mild wear; above $80 \mathrm{nN}$, the friction increases sharply, indicating that severe wear occurred at relatively high loads. The friction curve for the PEI surface is relatively smoother, unfortunately, a sharp increase in the friction is also observed at $80 \mathrm{nN}$. In other words, when the external load reaches $80 \mathrm{nN}$, the friction force increases faster than that linearly extrapolated, which reflects that wear or displacement of PEI materials also occurs in this case. For a $\mathrm{Si}_{4} \mathrm{~N}_{3}$ tip with radius of $-50 \mathrm{~nm}$ used in this work, the observed threshold loads of $80 \mathrm{nN}$ is roughly estimated corresponding to a pressure of $-0.9 \mathrm{GPa}$. Contrary to the above, the friction curve for the HFBA-derivatized thin film is smooth and linear within the tested loads, which indicates that the HFBA-derivatized thin film has excellent friction-reducing and anti-wear abilities. The adhesion and friction results indicate that the 
tribological properties of the polymer film can be well improved by chemisorbing molecules with low surface energy.

From Fig. 3, we also can see that a large non-zero friction signal is recorded at a zero external load for the hydroxylated silicon surface, which is attributed to the jump-to-contact instability governed by the attractive forces (such as the van der Walls force) during the approach of the tip to the sample surface. In other words, interaction between the tip and sample surface has been existed even if the external load is zero. Such interaction is close related to the adhesion, which has a significant contribution to the friction force especially in the very low loads. The jump of the tip onto the surface becomes weaker for the PEI surface and even disappears for the HFBA-derivatized thin film. Such observations are well consistent with the adhesive test results.

\subsection{Thermal stability}

Since most MEMS packaging processes contain steps at elevated temperatures, it is imperative to investigate the thermal stability of potential films for MEMS application. Thus, the thermal stability of the HFBA-derivatized thin film was examined by heating the samples in an oven for a heating duration of $60 \mathrm{~min}$ in air. The contact angles after heating as functions of the heating temperature are shown in Fig. 4. It is seen that the HFBA-derivatized film is able to survive heat treatment up to $-380{ }^{\circ} \mathrm{C}$. This

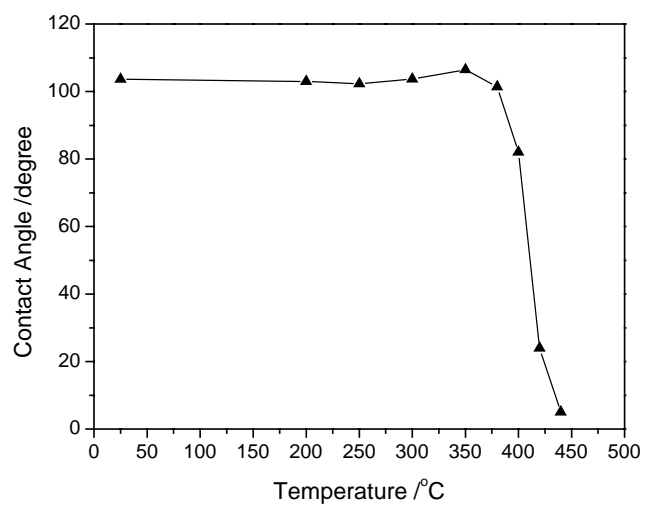

Fig. 4. Variation of water contact angles with the heating temperatures for the HFBA-derivatized film heat for duration of $60 \mathrm{~min}$. observation is similar to what was reported by Srinivasan et al. [34] that the fluorinated SAMs (FDTSSAMs) could withstand a temperature of $400{ }^{\circ} \mathrm{C}$ in air and $500{ }^{\circ} \mathrm{C}$ in $\mathrm{N}_{2}$, while the hydrocarbon SAMs (OTSSAMs) degraded in air above $100{ }^{\circ} \mathrm{C}$ although it could keep stable up to $450{ }^{\circ} \mathrm{C}$ in $\mathrm{N}_{2}$. A common pathway for the decomposition of hydrocarbons at ambient condition is through the dehydrogenation of the $\mathrm{C}-$ $\mathrm{H}$ bond, while fluorocarbons usually cleave at the $\mathrm{C}-\mathrm{C}$ bond leaving the strong $\mathrm{C}-\mathrm{F}$ bond intact [34].

\section{Conclusions}

The HFBA-derivatized film was generated on the PEI surface in the presence of a chemical amide bond. Due to the hydrophobicity and low surface energy, the HFBA-derivatized film possessed good friction-reducing and adhesion-resistant behavior, with the adhesive force to be only about $5.5 \mathrm{nN}$ (a pyramidal $\mathrm{Si}_{3} \mathrm{~N}_{4}$ tip with radius of curvature about $50 \mathrm{~nm}$ was used to measure the adhesion), which was more than one order of magnitude lower than that of the silicon substrate surface. Besides, the HFBA-derivatized film could withstand a temperature of $380{ }^{\circ} \mathrm{C}$ in air. Thus, a good alternative method was presented to improve the tribological properties of polymer film by chemisorbing molecules with low surface energy. This makes it feasible for the derivatized polymer film to find promising application in resolving the tribological problems of micro-electromechanical systems.

\section{Acknowledgements}

The authors would like to express their sincere thanks to Dr. Xudong Xiao (Department of Physics, Hongkong University of Technology and Science) for his kindness of offering the AFM/FFM facility. We also wish to acknowledge the financial support from National Natural Science Foundation of China (Grant Nos. 50375151, 50275142, 50272068), and the " 863 " project (2002AA302609).

\section{References}

[1] Z. Rymuza, Microsyst. Technol. 5 (1999) 173. 
[2] Y.P. Zhao, L.S. Wang, T.X. Yu, J. Adhes. Sci. Technol. 17 (2003) 519.

[3] Y.P. Zhao, Acta Mechanica Sinica 19 (2003) 1.

[4] H.N.T. Le, B. Garcia, C. Deslouis, X.Q. Le, J. Appl. Electrochem. 32 (2002) 105.

[5] X.P. Wang, O.K.C. Tsui, X.D. Xiao, Langmuir 18 (2002) 7066.

[6] A. Casoli, M. Brendlé, J. Schultz, P. Auroy, G. Reiter, Langmuir 17 (2001) 388.

[7] C. Ton-That, D.O.H. Teare, R.H. Bradley, Chem. Mater. 12 (2000) 2106.

[8] V.V. Tsukruk, F. Rinderspacher, V.N. Bliznyuk, Langmuir 13 (1997) 2171.

[9] A. Mueller, T. Kowalewski, K.L. Wooley, Macromolecules 31 (1998) 776.

[10] X.Y. Zhang, J. Klein, S.S. Sheiko, A.M. Muzafarov, Langmuir 16 (2000) 3893.

[11] X.Y. Zhang, M. Wilhelm, J. Klein, M. Pfaadt, E.W. Meijer, Langmuir 16 (2000) 3884.

[12] G. Decher, J.D. Hong, J. Schmitt, Thin Solid Films 210-211 (1992) 831.

[13] Y. Lvov, G. Decher, H. Mohwald, Langmuir 9 (1993) 481.

[14] J.C. Chen, L. Huang, L.M. Ying, G.B. Luo, X.S. Zhao, W.X. Cao, Langmuir 15 (1999) 7208.

[15] M.F. Rubner, M. Ferreira, Macromolecules 28 (1995) 7107.

[16] A. Chilkoti, B.D. Ratner, Surf. Interface Anal. 17 (1991) 567.

[17] R.P. Popat, I. Sutherland, E.S. Sheng, J. Mater. Chem. 5 (1995) 713.

[18] J.J. Chance, W.C. Purdy, Langmuir 13 (1997) 4487.

[19] I. Sutherland, E. Sheng, D.M. Brewis, R.J. Heath, J. Mater. Chem. 4 (1994) 683.

[20] A.P. Ameen, R.J. Ward, R.D. Short, G. Beamson, D. Briggs, Polymer 34 (1993) 1795.

[21] A. Chilkoti, B.D. Ratner, D. Briggs, Chem. Mater. 3 (1991) 51.

[22] P. Böhme, H.G. Hicke, M. Ulbricht, J.H. Fuhrhop, J. Appl. Polym. Sci. 55 (1995) 1495.

[23] P. Böhme, G. Vedantham, T. Przybycien, G. Belfort, Langmuir 15 (1999) 5323.
[24] R. Bahulekar, N.R. Ayyangar, S. Ponrathnam, Enzyme Microb. Technol. 13 (1991) 858.

[25] M.Y. Gao, B. Richter, S. Kirstein, Adv. Mater. 9 (1997) 802.

[26] S.-L. Ren, S.-R. Yang, Q.-J. Xue, Acta Physico-Chimica Sinica 17 (2001) 97 (in Chinese).

[27] S.-L. Ren, S.-R. Yang, J.-Q. Wang, S.-K. Qi, Y.P. Zhao, Acta Chim. Sinica 59 (2001) 1894 (in Chinese).

[28] D.A. Hutt, G.J. Leggett, Langmuir 13 (1997) 2740.

[29] C.D. Bain, E.B. Troughton, Y.T. Tao, J. Evall, G.M. Whitesides, R.G. Nuzzo, J. Am. Chem. Soc. 111 (1989) 321.

[30] J. Peeling, F.E. Hruska, N.S. Mclntyre, Can. J. Chem. 56 (1978) 1555.

[31] V.V. Tsukruk, M.P. Everson, L.M. Lander, W.J. Brittain, Langmuir 12 (1996) 3905.

[32] X.D. Xiao, L.M. Qian, Langmuir 16 (2000) 8153.

[33] CRC Handbook of Solubility Parameters and Other Cohesion Parameters, CRC Press, Boca Raton, 1983, p. 427.

[34] U. Srinivasan, M.R. Houston, R.T. Howe, R. Maboudian, J. Microelectromech. Syst. 7 (1998) 252.

[35] G. Luengo, S.E. Campbell, V.I. Srdanov, F. Wudl, J.N. Israelachvili, Chem. Mater. 9 (1997) 1166.

[36] C.D. Frisbie, L.F. Rozanyal, A. Noy, M. Wrighton, C.M. Lieber, Science 265 (1994) 2071.

[37] A. Noy, D.C. Frisbie, L.F. Rozsnyai, M.S. Wrighton, C.M. Lieber, J. Am. Chem. Soc. 117 (1995) 7943.

[38] H. Yoshizawa, Y.L. Chen, J. Israelachvili, J. Phys. Chem. 97 (1993) 4128.

[39] H. Yoshizawa, Y.L. Chen, J. Israelachvili, Wear 168 (1993) 161.

[40] H. Yoshizawa, J. Israelachvili, J. Phys. Chem. B 102 (1998) 234.

[41] B.M. Zhang Newby, M.K. Chaudhury, H.R. Brown, Science 269 (1995) 1407.

[42] M. Graupe, T. Koini, H.I. Kim, N. Garg, Y.F. Miura, M. Takenaga, S.S. Perry, T.R. Lee, Mater. Res. Bull. 34 (1999) 447.

[43] H.I. Kim, M. Graupe, O. Oloba, T. Koini, S. Imaduddin, T.R. Lee, S.S. Perry, Langmuir 15 (1999) 3179. 